\title{
Apolipoprotein E Binds to and Potentiates the Biological Activity of Ciliary Neurotrophic Factor
}

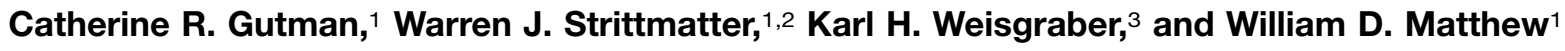 \\ Departments of ${ }^{1}$ Neurobiology and ${ }^{2}$ Medicine (Neurology) and Joseph and Kathleen Bryan Alzheimer's Disease Research \\ Center, Duke University Medical Center, Durham, North Carolina 27710, and ${ }^{3}$ Gladstone Institute of Cardiovascular \\ Disease, Cardiovascular Research Institute, Department of Pathology, University of California, \\ San Francisco, California 94140
}

Expression of apolipoprotein $\mathrm{E}$ (apoE) and ciliary neurotrophic factor (CNTF), a pleiotropic neuron survival factor, increases in the CNS in response to injury. Although CNTF is believed to act as a survival factor after injury in the CNS, the functions of apoE in the CNS remain mainly unknown. Similarities between apoE and CNTF, including coinciding patterns of postinjury expression, extracellular localization, homologous tertiary structure, and ability to form homodimers led us to examine the possibility that apoE and CNTF directly associate and thereby facilitate the neurotrophic activity of CNTF. We identified two binding interactions between apoE and CNTF: (1) reversible binding of both the apoE3 and apoE4 isoforms to CNTF under nondenaturing conditions, and (2) a higher avidity, SDS-stable binding of apoE3 with CNTF. Purified lipid-free apoE, as well as apoE in cerebrospinal fluid, binds CNTF. We demonstrate here that the survival-promoting activity of CNTF on cultured hippocampal neurons is potentiated by apoE. In the absence of apoE, survival of hippocampal neurons with $1 \mathrm{ng} / \mathrm{ml}$ CNTF was $20 \%$ above control survival values. In contrast, in the presence of apoE, survival of hippocampal neurons with $1 \mathrm{ng} / \mathrm{ml}$ CNTF was $40 \%$ above control survival values. These data, which indicate a novel function for apoE in the nervous system, support the hypothesis that apoE secreted locally at sites of injury can facilitate neural repair by promoting the activity of certain growth factors, in particular CNTF.

Key words: apoE; CNTF; neuron survival; protein binding; cytokine; hippocampal neurons
Apolipoprotein E (protein, apoE; allele, APOE) is the principal apolipoprotein in the brain (for review, see Mahley, 1988) and CSF (Pitas et al., 1987). Several observations have implicated a role for apoE in the injured nervous system. Expression of apoE mRNA by astrocytes in the hippocampus increases after entorhinal cortex lesion (Poirier et al., 1991). Oligodendrocytes and macrophages increase expression of apoE after optic and sciatic nerve injury, respectively (optic, Stoll et al., 1989) (sciatic, Skene and Shooter, 1983; Stoll and Mueller, 1986), and apoE protein accumulates to $5 \%$ of total extracellular protein after peripheral nervous system (PNS) injury (Skene and Shooter, 1983). APOE is a susceptibility gene for familial and late-onset Alzheimer's disease [AD; Strittmatter et al. (1993a); for review, see Strittmatter and Roses (1995)]. The gene dose of APOE4, one of the three major alleles of APOE in humans, is correlated with increased risk and decreased average age of onset of AD. These observations suggest a role for apoE in the injured or diseased nervous system.

Three major isoforms of apoE in humans-apoE2, apoE3, and apoE4-are distinguished by cysteine-arginine substitutions at

Received Jan. 8, 1997; revised May 30, 1997; accepted June 4, 1997.

This work was supported by the Joseph Bryan Scholar Fund (C.R.G.), National Institutes of Health RO1 AG-12532 and the Alzheimer Association Zenith Award (W.J.S.), National Heart, Lung, and Blood Institute Program Project Grant HL 41633 (K.H.W.), the Alzheimer Association Grant IIRG 94-072 (W.D.M.), and GlaxoWellcome (W.D.M. and W.J.S.). We thank Regeneron Pharmaceuticals for generously providing CNTF for this project, Dr. Don Lo for helpful comments on this manuscript, and Dr. Ann Saunders for genotyping the CSF samples. The excellent technical assistance of Daryl E. Jones is gratefully acknowledged.

Correspondence should be addressed to Dr. William D. Matthew, Department of Neurobiology, Box 3209, Duke University Medical Center, Durham, NC 27710.

Copyright (C) 1997 Society for Neuroscience $\quad 0270-6474 / 97 / 176114-\bullet \$ 05.00 / 0$ positions 112 and 158. The most common isoform, apoE3, is secreted as a 299 amino acid protein with a single cysteine at position 112 and an arginine at position 158; apoE2 contains a cysteine at position 158, and apoE4 contains an arginine at position 112. ApoE contains two distinct structural and functional domains, a hydrophobic domain and a hydrophilic receptorbinding domain (Weisgraber, 1994). The crystal structure of the hydrophilic domain of apoE is homologous to the structurally related family of four-helix bundle growth factors, including ciliary neurotrophic factor [CNTF; for review, see Bazan (1991); Mott and Campbell (1995); apoE crystal structure by Wilson et al. (1991); CNTF crystal structure by McDonald et al. (1995)]. Both apoE and CNTF form homodimers, suggesting that these two proteins might form a heterodimer.

The cellular expression pattern of CNTF parallels that of apoE. CNTF expression in astrocytes is upregulated near sites of injury in the CNS (Ip et al., 1993), and myelinating Schwann cells in the PNS contain high levels of cytoplasmic CNTF (Rende et al., 1992) that is released after nerve injury. CNTF immunoreactivity and biological activity in peripheral nerve are detectable extracellularly for $7 \mathrm{~d}$ after PNS injury (Sendtner et al., 1992). CNTF exerts a broad range of biological activities, many of which suggest that CNTF acts as an injury-associated survival factor in the nervous system (for review, see Adler, 1993). In vivo, CNTF supports the survival of intermediolateral column spinal cord neurons after adrenal medulla lesion (Blottner et al., 1989), reduces the axotomy-induced death of facial nucleus neurons (Sendtner et al., 1990), and potentiates peripheral nerve regeneration (Sahenk et al., 1994). In vitro, CNTF promotes the survival of many neuronal cell types, including sensory and sympa- 
thetic ganglion neurons of the PNS [sensory, Skaper and Varon (1986); sympathetic, Saadat et al. (1989)], cerebellar neurons (Larkfors et al., 1994), and embryonic hippocampal neurons (Ip et al., 1991).

In the present study we sought to determine whether apoE and CNTF functionally interact. We show that apoE binds CNTF and potentiates the in vitro survival-promoting activity of CNTF on embryonic rat hippocampal cultures.

\section{MATERIALS AND METHODS}

\section{ApoE/CNTF binding assays}

Gel-shift assays. Delipidated apoE was purified from individuals homozygous for apoE3 or apoE4, as previously described (Rall et al., 1986). ApoE3 or apoE4 was incubated with recombinant human CNTF (generously provided by Regeneron Pharmaceuticals, Tarrytown, NY) in Tris-buffered saline (TBS; see figure legends for specifics on quantities of proteins) for up to $4 \mathrm{hr}$ at $37^{\circ} \mathrm{C}$. ApoE also was incubated with control growth factors: leukemia inhibitory factor (LIF), a member of the fourhelix bundle family of growth factors; NT3, a member of the neurotrophin family; and the basic fibroblast growth factor bFGF (LIF, R \& D Systems, Minneapolis, MN; NT3, Regeneron Pharmaceuticals; bFGF, Collaborative Biomedical Products, Bedford, MA). Incubations were terminated by adding $4 \times$ SDS-Laemmli buffer without reducing agents. Proteins were separated electrophoretically by SDS-PAGE (see figures for percentage of polyacrylamide gels) and transferred to polyvinylidene fluoride (PVDF) membrane (Immobilon P, Millipore, Bedford, MA). The membranes were blocked in Blotto [5\% dried milk in TBS, pH 7.6, with $0.05 \%$ Tween (Surfact Amps-20, Pierce, Rockford, IL)] for 1 hr and then incubated in primary antibody for $1 \mathrm{hr}$. The anti-apoE antibody was a polyclonal goat anti-human apoE (Calbiochem, San Diego, CA) diluted 1:2000 in Blotto. The anti-human CNTF antibody was a monoclonal antibody (R \& D Systems) diluted 1:2000 in Blotto. Membranes were washed in Blotto three times, $10 \mathrm{~min}$ for each wash, and then incubated with the secondary antibody for $1 \mathrm{hr}$. All incubations and washes were done at $25^{\circ} \mathrm{C}$. For the detection of anti-apoE antibody, the secondary antibody was a swine anti-goat IgG conjugated to horseradish peroxidase (HRP; Boehringer Mannheim Biochemicals, Indianapolis, IN) diluted 1:3000 in Blotto. The secondary antibody for the anti-CNTF antibody was an HRP-conjugated goat anti-mouse IgG F(ab) (Boehringer Mannheim Biochemicals) diluted 1:1500 in Blotto. The enzyme-conjugated antibodies were visualized by the addition of ECL chemiluminescent substrate (Amersham, Arlington Heights, IL) and exposure to Hyperfilm (Amersham), as previously described (Strittmatter et al., 1993a).

To determine whether apoE in human CSF forms a complex with CNTF, we added $500 \mathrm{ng}$ of CNTF to $10 \mu \mathrm{l}$ of human CSF. CSF samples were collected by diagnostic lumbar puncture after informed consent. Eight samples of $\mathrm{CSF}$ that previously had been genotyped for apoE isoform and stored at $-80^{\circ} \mathrm{C}$ were used. In addition, two freshly collected samples of $\mathrm{CSF}$, stored at $4^{\circ} \mathrm{C}$, were tested. The genotype of these latter two samples was not determined, but the apoE dimer on nonreduced gels indicated the presence of at least one APOE3 or APOE2 allele. Samples were processed and immunoblots run as described above.

Substrate-capture immunoblot (SCIB) assay. ApoE3 or apoE4 (300 ng) in $20 \mu \mathrm{l}$ of TBS was incubated in polypropylene tubes (Eppendorf, Hamburg, Germany) for $1 \mathrm{hr}$; then unbound apoE was washed away with five changes of TBS. ApoE-coated and control tubes were blocked with $100 \mu \mathrm{l}$ of $2 \%$ BSA (Sigma, St Louis, MO) for $1 \mathrm{hr}$ and washed five times with TBS. CNTF (300 ng in $20 \mu \mathrm{l}$ of Tris- $1 \mathrm{M} \mathrm{NaCl}$ ) was incubated in apoE-coated tubes and in control tubes for $2 \mathrm{hr}$ at $37^{\circ} \mathrm{C}$. Unbound CNTF was removed with five washes of Tris- $1 \mathrm{M} \mathrm{NaCl}$. After a final wash with TBS, $4 \times$ nonreducing Laemmli buffer was added to remove bound proteins from the tubes. Proteins were separated on $10 \%$ polyacrylamide gels (precast gels from Bio-Rad, Hercules, CA), transferred, blocked, and probed with anti-CNTF antibody as described above.

To strip the membranes for reprobing with anti-apoE antibody, we fixed the proteins to the PVDF membrane with $50 \%$ methanol/10\% acetic acid before blocking with Blotto. After the membranes were probed with anti-CNTF antibody, the membranes were stripped in 200 mM glycine-HCL with $0.05 \%$ Tween, $\mathrm{pH} 2.5$, at $80^{\circ} \mathrm{C}$ for $1 \mathrm{hr}$. Membranes were processed in ECL and exposed to film to insure that there was no residual signal from the HRP-conjugated secondary antibody. Then the membranes were blocked and probed with anti-apoE antibody, as described above.

\section{Hippocampal bioassays}

Substrates for cell culture. The 96-well plates were coated with $100 \mu \mathrm{l}$ of $10 \mu \mathrm{g} / \mathrm{ml}$ poly-D-lysine (PDL) for $3 \mathrm{hr}$ at room temperature. Wells were washed with sterile water three times, plated with $100 \mu \mathrm{l}$ of $10 \mu \mathrm{g} / \mathrm{ml}$ laminin diluted in HBSS (Life Technologies, Gaithersburg, MD), and incubated overnight at $37^{\circ} \mathrm{C}$. On the morning of culture the plates were washed three times with Opti-MEM (Life Technologies). ApoE3 or apoE4 were prepared in Opti-MEM at a concentration of $1 \mathrm{ng} / \mathrm{ml}$, and $100 \mu \mathrm{l} /$ well was incubated in the PDL/laminin-coated wells at $37^{\circ} \mathrm{C}$. After $3 \mathrm{hr}$ the wells were washed with three changes of Opti-MEM to remove unbound apoE. Serial dilutions of CNTF $(0.004-25 \mathrm{ng} / \mathrm{ml}$ in Opti-MEM) were added to the plates $3 \mathrm{hr}$ before the cells were dissociated; then $100 \mu \mathrm{l}$ of cell suspension was added to the wells, bringing the final volume of media to $200 \mu \mathrm{l} /$ well.

Preparation and plating of rat embryonic hippocampal neurons. Dissociated hippocampal neurons were prepared with a modification of a previously described method (Banker and Cowen, 1977; Goslin and Banker, 1991). Hippocampi were dissected from embryonic day 18 (E18) rats. To minimize the number of contaminating astrocytes, we carefully dissected the hippocampus to avoid the overlying cortex. The meninges were removed, and the cells were incubated in $\mathrm{Ca}^{2+}, \mathrm{Mg}^{2+}$-free HBSS (Life Technologies) with $0.005 \%$ (w/v) trypsin at $37^{\circ} \mathrm{C}$ for $15 \mathrm{~min}$. The cells were washed and triturated in DMEM/F12 medium (Life Technologies) with $10 \%$ fetal calf serum (Life Technologies). The cells were pelleted by centrifugation and resuspended in Opti-MEM with $1 \%$ N2 supplement (Life Technologies). Cells were counted and resuspended to a final concentration of $5 \times 10^{6}$ cells $/ \mathrm{ml}$ and plated at an initial density of 50,000 cells/well. AlbuMAX I (Life Technologies) was added as a supplement at a final concentration of $2 \mathrm{mg} / \mathrm{ml}$. Cells were cultured for $72 \mathrm{hr}$ at $37^{\circ} \mathrm{C}$ in $5 \% \mathrm{CO}_{2}$.

Images of the hippocampal cultures were collected after $72 \mathrm{hr}$ in vitro by viewing the cultures under phase through a $32 \times$ objective on a Zeiss inverted microscope (Oberkochen, Germany). Cultures were photographed with Kodak TMAX film (Rochester, NY).

MTS survival assay. Viability was assayed after $72 \mathrm{hr}$ in vitro by the Promega viability assay (CellTiter 96 AQueous, Promega, Madison, WI) (Ip and Yancopoulos, 1992; Riddle et al., 1995). This is a colorimetric assay in which the tetrazolium compound [3-(4,5-dimethylthiazol-2-yl)5-(3-carboxymethoxyphenyl)-2-(4-sulfophenyl)2H-trazolium (MTS)] is reduced by viable cells into a soluble formazan product. The absorbance of the formazan is measured directly from the 96-well plates. The quantity of formazan product as measured by absorbance at $490 \mathrm{~nm}$ is proportional to the number of viable cells. For performing this assay, we removed $100 \mu \mathrm{l}$ of media from each well before adding $20 \mu \mathrm{l}$ of MTS solution to each well. Plates were returned to the incubator, and absorbance was read by a Dynatech MR5000 microplate reader (Dynatech Laboratories, Alexandria, VA) after a $4 \mathrm{hr}$ incubation. The data were collected and calculated as the percentage of difference between each treatment group and the matched control (no apoE/no CNTF condition) for each experiment. The value for the no apoE/no CNTF condition was set at $100 \%$. Then the percentages of differences for the separate experiments were averaged.

\section{RESULTS}

\section{ApoE binds to CNTF}

Substrate-capture immunoblot (SCIB) assay was used to test whether CNTF binds apoE. This SCIB assay took advantage of the fact that apoE readily absorbs to plastic surfaces, presumably because of hydrophobic interactions. Purified, renatured lipidfree apoE3 or apoE4 isolated from human serum was bound to microfuge tubes, blocked with BSA, and then incubated with recombinant human $\mathrm{CNTF}$. As a control for nonspecific binding of CNTF we incubated CNTF in a BSA-blocked tube, without apoE. After washing away unbound CNTF with $1 \mathrm{~m} \mathrm{NaCl-Tris,}$ we stripped the retained proteins by adding nonreducing Laemmli buffer and separated the proteins by SDS-PAGE. Western blots were probed with an anti-CNTF antibody and then stripped and reprobed with an anti-apoE antibody. Figure 1 shows that CNTF was retained when apoE3 or apoE4 were first bound to the tube. Both CNTF monomer and homodimer were retained by apoE. In contrast, there was essentially no binding of CNTF to 


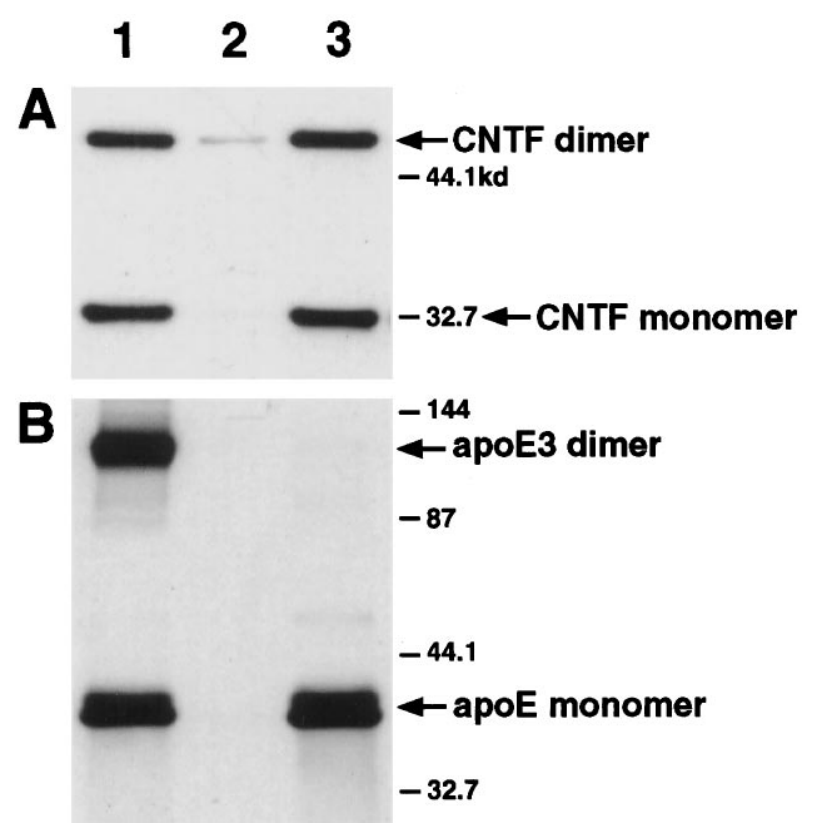

Figure 1. ApoE3 and apoE4 bind CNTF. Western blot of retained CNTF in the SCIB assay shows that CNTF binds to apoE3- or apoE4coated microfuge tubes. CNTF was incubated in tubes precoated with apoE3 (lane 1) or apoE4 (lane 3) or in tubes with no apoE (lane 2). All tubes were blocked with BSA before CNTF was added. Unbound or weakly associated protein was removed by washing with $1 \mathrm{M} \mathrm{NaCl}$; then bound proteins were stripped from the tubes with nonreducing Laemmli buffer, and the proteins were separated on a $10 \%$ SDS-polyacrylamide gel (nonreducing). The Western blot was probed with anti-CNTF antibody $(A)$ and then stripped and reprobed with anti-apoE antibody $(B)$. The positions of molecular weight standards are shown (right). Note that these were nonreduced samples, and protein mobility does not correlate precisely with molecular weights. The positions of the apoE monomer, apoE3 dimer, and CNTF monomer and dimer are shown (right, arrows).

the BSA-blocked surface: only a trace amount of CNTF homodimer was detected from the BSA-blocked control tube. These data demonstrate that both isoforms of apoE bind CNTF monomer and dimer, even at high salt concentrations.

\section{ApoE3 forms an SDS-stable complex with CNTF}

We have characterized a number of apoE-protein interactions (e.g., $\tau, \beta$-amyloid, and laminin; for review, see Strittmatter and Roses, 1995) that are stable in ionic detergent. Because of the structural homology between CNTF and the amino terminal domain of apoE and because apoE3 and CNTF each forms SDS-stable homodimers (Fig. 1), we tested whether apoE and CNTF can form an SDS-stable heterocomplex. We incubated purified apoE3 or apoE4 with recombinant human CNTF in solution. Incubating apoE3 with CNTF produced a new protein species detected by SDS-PAGE with an apparent molecular weight consistent with a bimolecular apoE3/CNTF complex (Fig. $2 \mathrm{~A}$; molecular mass of apoE is $34 \mathrm{kDa}$ and of CNTF is $24 \mathrm{kDa}$ ). This species was not seen with apoE3, apoE4, or CNTF alone (Fig. $2 B$ ). Incubating apoE4 with $\mathrm{CNTF}$ did not produce this new species (Fig. 2B). To confirm that this was an apoE3/CNTF complex, we probed Western blots with anti-apoE and antiCNTF antibodies. The presumed apoE3/CNTF complex was immunoreactive for both anti-apoE and anti-CNTF antibodies (Fig. $2 A$ ). The apoE3/CNTF complex could be detected within 30 min of incubation and reached a maximum at 3-4 hr (Fig. 3). No apoE3/CNTF complex was detected when the reducing agent $\beta$-mercaptoethanol ( $\beta$-ME) was included in the Laemmli buffer, suggesting that the complex is linked by a disulfide bond (data not shown).

We tested several other growth factors for their ability to bind apoE. LIF, a four-helix bundle growth factor with structural homology to CNTF and to apoE, and the structurally distinct growth factors NT3 and bFGF were incubated with apoE3, and the proteins were separated by SDS-PAGE. None of these growth factors formed a complex with apoE3, as detected by gel-shift assay (Fig. 3).

Complex formation between proteins can be an artifact produced by boiling in nonreducing Laemmli buffer (Kumar and Davidson, 1992). Two experiments indicated that the apoE3/ CNTF complex was produced during incubation and not during boiling. First, complex formation was observed whether or not the proteins were boiled in nonreducing Laemmli buffer (data not shown). Second, the amount of complex formed was dependent on the incubation time (Fig. 3) and not on whether the samples were boiled or on the duration of boiling.

\section{ApoE3 in human cerebrospinal fluid (CSF) forms a complex with CNTF}

As demonstrated above, purified serum-derived apoE can bind CNTF. Next, we wanted to determine whether native apoE in CSF binds to CNTF, even in the presence of other proteins. The SCIB assay described above (see Fig. 1) is not appropriate for this experiment: if the mixture of proteins in CSF were absorbed to a microf uge tube, we could not determine whether CNTF bound apoE or some other CSF protein. However, because the apoE3/ CNTF complex can be identified by SDS-PAGE, we could determine whether apoE in CSF binds CNTF under this assay condition. CSF samples from five APOE3/3 individuals and from three APOE4/4 individuals were tested for their ability to produce an apoE/CNTF complex. All samples of CSF from APOE3 homozygous individuals produced an apoE/CNTF complex with exogenous CNTF (Fig. 4). The apoE monomer sometimes is resolved as a doublet at $\sim 34 \mathrm{kDa}$ because of differences in post-translational sialation of apoE (Zannis et al., 1984). In many of our gels, as in Figure 4, the apoE3/CNTF complex was resolved as a doublet, suggesting that CNTF binds both sialyated and nonsialyated apoE3. No CSF samples from APOE4/4 individuals formed an SDS-stable apoE4/CNTF complex (data not shown).

Because the CSF samples described above had been stored frozen (freezing can denature lipoprotein particles), we tested whether apoE in fresh CSF, and therefore lipid-bound, would form a complex with CNTF. Two samples of freshly collected CSF were incubated with CNTF and probed for the presence of an apoE/CNTF complex. In both cases we observed complex formation that was indistinguishable from the complex generated in the frozen samples, indicating that apoE in a lipid particle can bind CNTF. These results support the conclusion that apoE3, and not apoE4, forms an SDS-stable apoE/CNTF complex. Most importantly, however, we have demonstrated that native apoE3 binds CNTF, even in the presence of the mixture of proteins in CSF.

\section{Effects of apoE on biological activity of CNTF in vitro}

Having found that both apoE3 and apoE4 can bind CNTF and that this binding occurs between native apoE and CNTF, we asked whether apoE alters the biological activity of CNTF. To assess the effect of apoE on the biological activity of CNTF, 
Figure 2. Gel-shift assays demonstrate the SDS-stable apoE3/CNTF complex. $A, \mathrm{CNTF}$ $(250 \mathrm{ng})$ and apoE3 or apoE4 (375 ng; equal molar amounts) were incubated alone or together, as indicated, in $50 \mu \mathrm{l}$ of TBS at $37^{\circ} \mathrm{C}$ for $3 \mathrm{hr}$. Proteins were separated on a 7.5\% SDS-polyacrylamide separating gel (nonreducing). The left three lanes of this Western blot were probed with an anti-apoE antibody while the right three lanes were probed with anti-CNTF antibody. The apoE3/CNTF complex is recognized by both antibodies, whereas apoE monomer and dimer are immunoreactive only with the anti-apoE antibody, and the CNTF multimers are recognized only by the anti-CNTF antibody. The samples were run on a $7.5 \%$ gel to resolve the apoE3/CNTF complex from the CNTF trimer. On a $7.5 \%$ gel the CNTF monomer is not resolved. The positions of molecular weight standards are indicated (right). Note that, under nonreducing conditions, protein mobility on SDS-PAGE may not correlate precisely with the molecular weights of proteins. $B$, Shown here, $500 \mathrm{ng}$ of purified and lipid-free apoE3 or apoE4 and $500 \mathrm{ng}$ of recombinant CNTF were incubated alone or in combination, as indicated. These samples were separated on a $10 \%$ SDSpolyacrylamide nonreducing gel. Western blots were probed with anti-apoE antibody. ApoE3, but not apoE4, forms a high-avidity complex with CNTF that resists denaturing.

we assayed the survival of cultured embryonic rat hippocampal neurons. Survival of E18 rat hippocampal neurons is supported by CNTF (Ip et al., 1991). However, these and other studies examining CNTF activity have included fetal bovine serum either during the initial plating of cells or throughout the experiments (Hughes et al., 1988; Ernsberger et al., 1989; Saadat et al., 1989; Arakawa et al., 1990; Magal et al., 1991, 1993; Ip et al., 1992; Unsicker et al., 1992). Because serum contains apoE $(\sim 30 \mu \mathrm{g} /$ $\mathrm{ml}$ ), we used a protocol that does not require serum during the initial plating of the hippocampal neurons or during culture (see Materials and Methods).

Neither apoE3 nor apoE4 alone significantly increased survival of hippocampal cells over control values (the absorbance value of the "no apoE/no CNTF" condition was the control value, and all data within each experiment were normalized to the control values of that experiment). However, both apoE3 and apoE4 significantly enhanced the survival-promoting activity of CNTF for E18 hippocampal cells. In the absence of apoE, $1 \mathrm{ng} / \mathrm{ml}$ CNTF promoted survival at a maximum of $20 \pm 2.5 \%$ over control survival (mean \pm SEM, average of four experiments; $n=$ 4-5/experiment) (Fig. 5A). Even at much higher concentrations of CNTF $(25 \mathrm{ng} / \mathrm{ml})$ there was no further increase in hippocampal neuron survival (survival at $25 \mathrm{ng} / \mathrm{ml} \mathrm{CNTF}$ was $18 \pm 4 \%$ over control). However, when apoE was bound to the plates before addition of CNTF, survival of hippocampal neurons was increased significantly. With apoE, CNTF promoted the survival of the hippocampal cultures in a dose-dependent manner: in the presence of apoE3 and apoE4, CNTF produced a maximum survival of $39 \pm 4.8 \%$ and $40 \pm 3.5 \%$ over controls, respectively

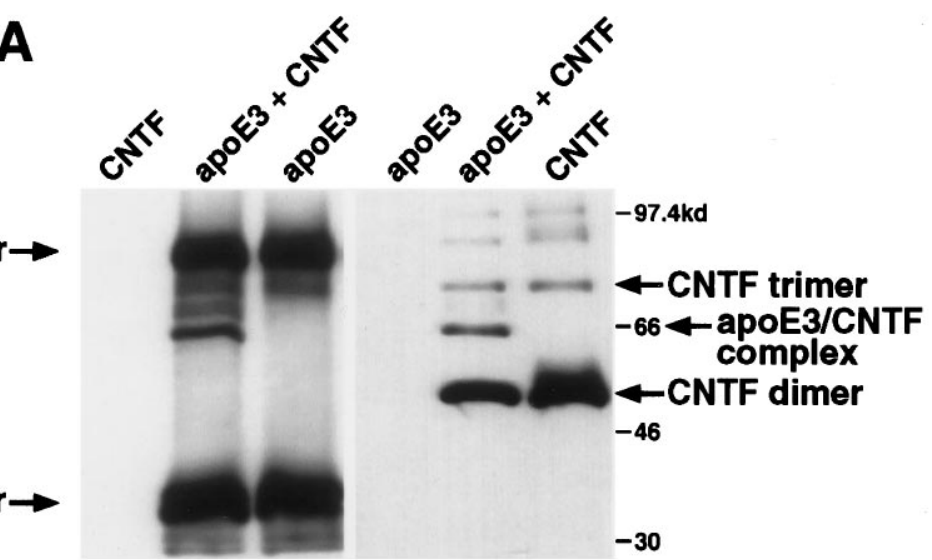

B

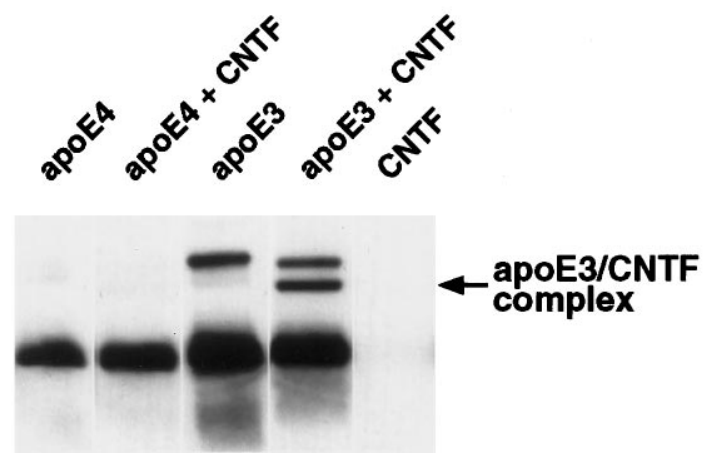

(the difference in maximum survival between the "apoE" and "no apoE" conditions was significant at $p<0.0005)$. In the presence and absence of apoE maximum survival was obtained at a CNTF concentration of $\sim 1 \mathrm{ng} / \mathrm{ml}$.

Surviving cells in all conditions had a healthy phase-bright appearance and extended long, branching neurites (Fig. 5B,C). Where isolated neurons were seen, there were no apparent differences in neuronal morphologies observed under the different culture conditions, although no detailed analysis of morphology was performed.

As a control, we tested whether MTS absorbance values were equivalent across the different culture conditions at $4 \mathrm{hr}$ after the hippocampal cultures were plated. MTS absorbance was tested in the presence and absence of $1 \mathrm{ng} / \mathrm{ml}$ apoE3 for the following CNTF concentrations: 0,1 , and $5 \mathrm{ng} / \mathrm{ml} \mathrm{CNTF.} \mathrm{For} \mathrm{the} \mathrm{no} \mathrm{apoE3}$ condition, MTS values at the tested CNTF concentrations were 0 $\mathrm{ng} / \mathrm{ml} \mathrm{CNTF}=0.351 \pm 0.002 ; 1 \mathrm{ng} / \mathrm{ml} \mathrm{CNTF}=0.356 \pm 0.006$; and $5 \mathrm{ng} / \mathrm{ml} \mathrm{CNTF}=0.359 \pm 0.007$. For the $1 \mathrm{ng} / \mathrm{ml}$ apoE3 condition the MTS absorbance values were $0 \mathrm{ng} / \mathrm{ml}$ CNTF = $0.353 \pm 0.003 ; 1 \mathrm{ng} / \mathrm{ml} \mathrm{CNTF}=0.353 \pm 0.01 ;$ and $5 \mathrm{ng} / \mathrm{ml}$ $\mathrm{CNTF}=0.35 \pm 0.01$. There were no significant differences among these conditions, indicating that differences in initial plating density did not account for differences in survival seen at $72 \mathrm{hr}$.

\section{DISCUSSION}

Although the roles of apoE and CNTF in injury have yet to be understood fully, both proteins are associated with the response to injury in the PNS and in the CNS. ApoE has been described classically as a lipid carrier protein, and one role of apoE after 


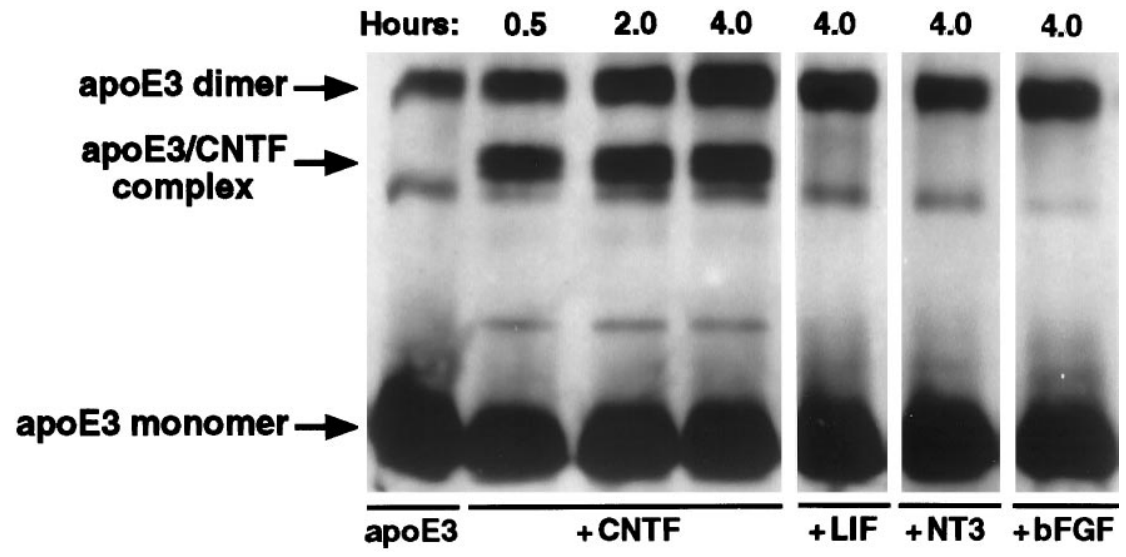

Figure 3. Time course and specificity of apoE3/CNTF complex formation. ApoE3 (50 ng) and CNTF, LIF, NT3, or bFGF (50 ng) were incubated together in $40 \mu \mathrm{l}$ of TBS for up to $4 \mathrm{hr}$. After the incubations were terminated at the indicated times, the samples were separated on a $10 \%$ SDS-polyacrylamide gel (nonreducing), and Western blots were probed with an anti-apoE antibody as described in Materials and Methods. ApoE/ CNTF complex was detectable within $30 \mathrm{~min}$ and reached a maximum by $4 \mathrm{hr}$. In contrast, no complex was detected between apoE and the growth factors LIF, NT3, or bFGF. injury may be to deliver lipid to regrowing axons. Although apoE probably does function in lipid delivery after injury (Ignatius et al., 1987; Boyles et al., 1989), our data suggest additional roles for apoE. We have shown that apoE binds CNTF and potentiates the survival-promoting activity of CNTF for hippocampal neurons. These data suggest a novel function for apoE in the nervous system: apoE acts as an accessory protein for $\mathrm{CNTF}$, potentiating the biological effects of CNTF.

Although the functional significance of CNTF was questioned when the CNTF knock-out mouse failed to show an obvious phenotype (Masu et al., 1993; DeChiara et al., 1995), recent experiments that used CNTF/LIF double knock-out mice have shown that LIF, which is structurally homologous to CNTF and uses the same $\beta$-receptor subunits as CNTF, can compensate for the loss of CNTF (Sendtner et al., 1996). Therefore, given that CNTF supports the survival of a wide variety of neuronal cell types, CNTF remains an important candidate as a neuronal survival factor after injury.

Our experiments demonstrate two distinct binding interactions between apoE and CNTF: reversible binding between CNTF and both apoE3 and apoE4, and SDS-stable irreversible binding between CNTF and apoE3. Both types of binding are of high avidity and specificity. First, as shown in the solid-phase SCIB assay, both apoE3 and apoE4 bind $\mathrm{CNTF}$ in $1 \mathrm{M} \mathrm{NaCl}$, with essentially no nonspecific binding of CNTF to BSA-blocked substrate. The ability of this binding to withstand $1 \mathrm{M} \mathrm{NaCl}$ indicates that apoE is tightly associated with CNTF. Both apoE3 and CNTF contain a single free cysteine, whereas apoE4 has no cysteine. Therefore, the reversible apoE/CNTF association observed with both apoE isoforms does not require disulfide bond formation. However, apoE3, and not apoE4, apparently is able to form a disulfide bond with CNTF. This SDS-stable complex between apoE3 and CNTF is formed by both delipidated apoE3 in solution and apoE3 within a lipoprotein particle in CSF. Native apoE3 in CSF forms a complex with exogenously added CNTF, supporting the hypothesis that apoE in the nervous system can bind CNTF. Furthermore, apoE in the complex environment of other proteins in CSF binds CNTF, indicating that the apoE3/ $\mathrm{CNTF}$ interaction is specific.

CNTF-supported survival of hippocampal neurons has been described previously (Ip et al., 1991) and is confirmed here. We found that CNTF, in the absence of apoE, modestly increased the survival of hippocampal neurons (maximum 20\% increase in survival over controls). However, there was an average twofold increase in the survival-promoting activity of $1 \mathrm{ng} / \mathrm{ml} \mathrm{CNTF} \mathrm{in}$ the presence of apoE3 or apoE4 (39 and 40\% increase over control in the presence of apoE3 and apoE4, respectively). This seems to be a specific effect of apoE on the activity of CNTF (and not simply an additive effect of the combined factors), because we found no significant effect of apoE alone on the survival of hippocampal neurons.

The presence of serum and contaminating astrocytes in previous studies may explain why no earlier reports found an effect of apoE on CNTF activity. Serum contains apoE, and astrocytes synthesize and secrete apoE. Thus, apoE was available for generating an apoE/CNTF complex in those experiments. Furthermore, astrocytes provide trophic support for hippocampal neurons in culture (Banker, 1980; Müller and Seifert, 1982). As astrocytes synthesize and possibly secrete CNTF (Kamiguchi et al., 1995), the combination of apoE and CNTF from astrocytes may support the survival of hippocampal neurons. In addition, an uncharacterized component of the ECM is required for CNTF to promote differentiation of O2A cells (Hughes et al., 1988; Lillien et al., 1990). ApoE can bind ECM via a variety of mechanisms, including binding to heparan-sulfate proteoglycans (Cardin et al., 1986; Weisgraber et al., 1986) and to laminin (Huang et al., 1995). Although we have no direct evidence that apoE is the ECM component required for CNTF function in the experiments of Lillien et al. (1990), apoE is a candidate.

Based on the binding between apoE and CNTF, three major hypotheses may explain the potentiation of CNTF by apoE. The simplest hypothesis explaining the functional consequence of binding between apoE and CNTF is that CNTF is tethered by apoE, thereby creating an effectively higher concentration of CNTF on the culture substrate. In vivo, such tethering by apoE could prevent CNTF from diffusing from sites of release, thus maintaining a local pool of available CNTF. This does not seem to be the most likely mechanism, however, because we found that even much higher concentrations of CNTF were not as efficacious as the combination of apoE and CNTF at supporting hippocampal culture survival. The second hypothesis is that by binding CNTF apoE may protect CNTF from chemical modifications such as oxidation or hydrolysis by proteases. Both apoE and $\mathrm{CNTF}$ accumulate at sites of injury, which are oxidative environments and sites of active metalloproteases and serine proteases. ApoE may mask proteolytic cleavage sites by binding CNTF, allowing CNTF to retain biological activity in a proteolytic environment.

The third hypothesis includes interactions between apoE and CNTF that could alter the binding affinity of CNTF for its receptor subunits. The functional CNTF receptor complex includes two $\beta$-subunits (gp130 and LIFR $\beta$, both of which are 


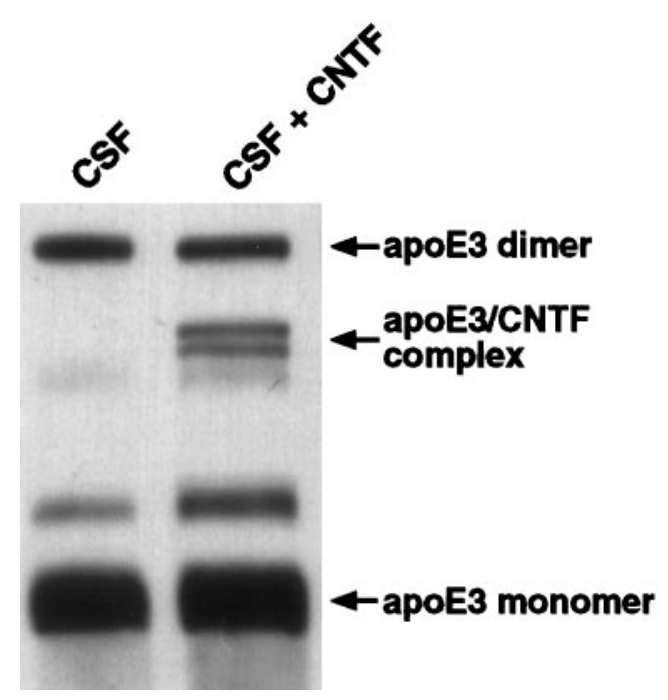

Figure 4. ApoE3 in CSF forms a complex with CNTF. CSF samples with no detectable CNTF or apoE3 immunoreactivity at the molecular weight of the apoE/CNTF complex were used. A representative sample of CSF is shown. Ten microliters of CSF were incubated alone or with 500 ng of exogenous $\mathrm{CNTF}$ at $37^{\circ} \mathrm{C}$ for $3 \mathrm{hr}$. Gel-shift assay with anti-apoE showed the formation of an apoE3/CNTF complex. Note that the apoE3/ CNTF complex is resolved as a doublet. This suggests that apoE3/CNTF complex formation is not affected by differences in post-translational sialation of apoE3.

shared by several members of the broadly acting family of fourhelix bundle growth factors; for review, see Davis et al., 1991; Ip and Yancopoulos, 1992) and one CNTF specific $\alpha$-subunit (Davis et al., 1993). Heterotrimerization of these receptor subunits by CNTF activates JAK/Tyk kinases associated with the $\beta$-receptor subunits (Stahl et al., 1994). These kinases in turn activate intracellular signaling molecules, including the STAT family of DNA binding transcription activators (for review, see Stahl and Yancopoulos, 1994). CNTF bound by apoE may stabilize binding interactions with some or all of its receptor subunits. If CNTF bound by apoE either is more efficient at recruiting its receptor subunits or forms a more stable receptor-ligand complex, then one would expect to observe potentiation of CNTF by apoE.

A final hypothesis does not depend on direct binding between apoE and CNTF. Instead, binding of apoE to its neuronal receptor, the low-density lipoprotein receptor-related protein (LRP), may activate an intracellular signaling cascade with synergy with the CNTF signaling pathway. Although it is not known whether apoE binding to the LRP receptor activates kinase activity, Nathan et al. (1994), Bellosta et al. (1995), and Holtzman et al. (1995) have demonstrated that the neurite-promoting effects of apoE3 in lipoprotein particles are facilitated via binding of apoE to the LRP receptor, suggesting downstream receptor-activated signaling.

We found no difference in our bioassays between apoE3 and apoE4 in their ability to potentiate the effects of CNTF, in agreement with our finding that both apoE isoforms bind CNTF in the SCIB assay under nondenaturing conditions. However, we also found a high-avidity SDS-stable complex between apoE3 and CNTF, but not between apoE4 and CNTF. [The mechanism of this high-avidity binding is not known, but because both apoE3 and CNTF contain a single cysteine and the apoE3/CNTF complex can be dissociated by $\beta$-ME, our data are consistent with disulfide bond formation. Dissociation of SDS-stable complexes
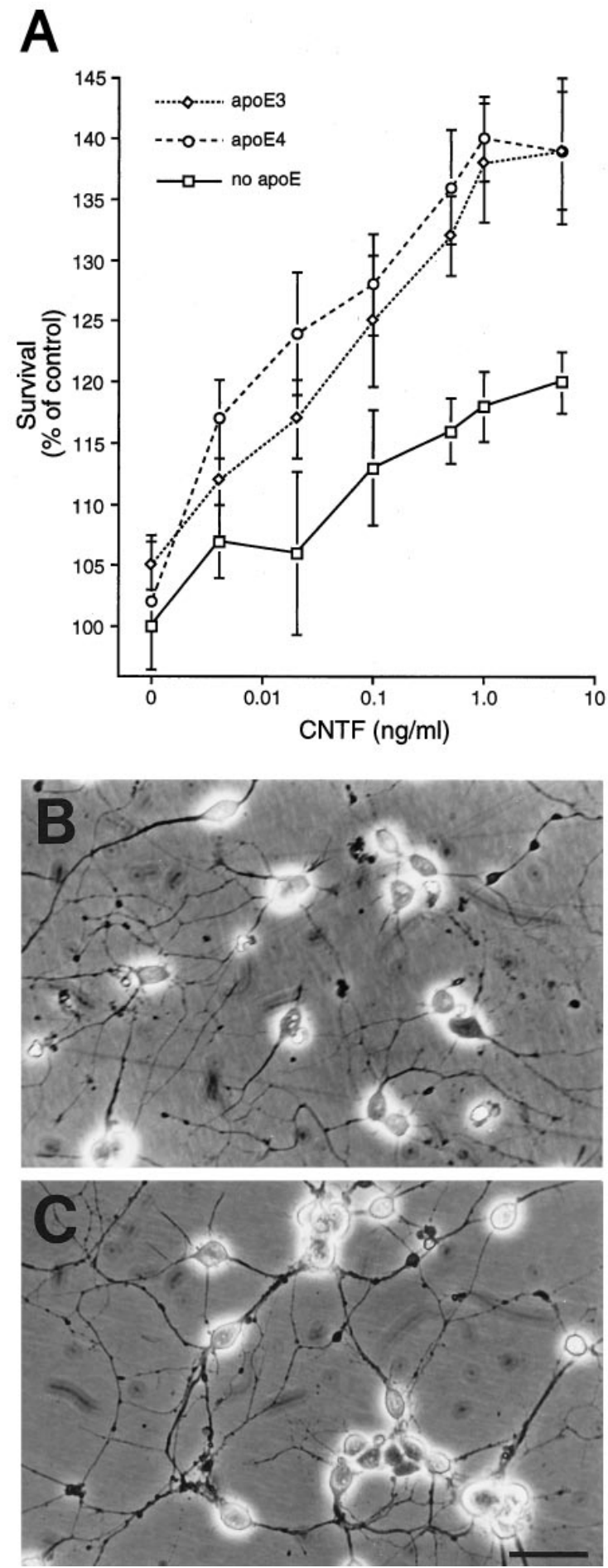

Figure 5. Dose-response effect of CNTF on survival of hippocampal neurons in the presence and absence of either apoE3 or apoE4. $A$, The 96-well plates were preplated with $1 \mathrm{ng} / \mathrm{ml}$ of apoE3 or apoE4. Control plates had no apoE. Dissociated hippocampal cells were cultured in the presence or absence of increasing concentrations of CNTF (0.004-25 $\mathrm{ng} / \mathrm{ml}$ ) for $3 \mathrm{~d}$. Survival was assayed at the end of the culture period by the MTS viability assay. The results from four independent experiments were pooled and are presented as the mean percentage of absorbance as compared with controls $\pm \operatorname{SEM}(n=4-5 /$ experiment $)$. The difference in maximum survival between apoE and no apoE conditions is significant at $p<0.0005$, using the Student's $t$ test for the differences between the means. $B, C$, Phase-contrast photomicrographs of hippocampal cultures after $3 \mathrm{~d}$ cultured in $40 \mathrm{pg} / \mathrm{ml} \mathrm{CNTF}$ in the presence $(B)$ or absence $(C)$ of $1 \mathrm{ng} / \mathrm{ml}$ apoE3. Calibration bar, $50 \mu \mathrm{M}$. 
by $\beta$-ME is not, however, proof of a disulfide bond, because other SDS-stable protein-protein interactions besides disulfide bonds can be dissociated by $\beta$-ME; for example, Strittmatter et al. (1993b).] The short-term bioassays presented in this report may not detect long-term differences in function between the apoE3 and apoE4 isoforms. Increasing evidence suggests that inheritance of the APOE4 allele is a liability, as compared with the APOE3 allele, for long-term recovery from neural injuries such as stroke (Connolly et al., 1996; Slooter et al., 1997; Laskowitz et al., 1997), cerebral hemorrhage (Alberts et al., 1996), or closed head injury (Sorbi et al., 1996). These types of nervous system injury often produce proteolytic and oxidative environments. Because apoE3 can form a higher avidity complex with CNTF than can apoE4, apoE3 may be able to bind and facilitate CNTF under oxidative conditions. In these cases apoE3 may have an increased ability to potentiate CNTF, thus leading to enhanced recovery.

\section{REFERENCES}

Adler R (1993) Ciliary neurotrophic factor as an injury factor. Curr Opin Neurobiol 3:785-789.

Alberts AJ, Graffagnino C, McClenny C, Delong WJ, Strittmatter WJ, Saunders AM, Roses AD (1996) Effect of apoE genotype on survival after intracerebral hemorrhage. Stroke 27:183A.

Arakawa Y, Sendtner M, Thoenen H (1990) Survival effect of ciliary neurotrophic factor (CNTF) on chick embryonic motoneurons in culture: comparison with other neurotrophic factors and cytokines. J Neurosci 10:3507-3515.

Banker GA (1980) Trophic interactions between astroglial cells and hippocampal neurons in culture. Science 209:809-810.

Banker GA, Cowen WM (1977) Rat hippocampal neurons in dispersed cell culture. Brain Res 126:397-425.

Bazan JF (1991) Neuropoietic cytokines in the hematopoietic fold. Neuron 7:197-208.

Bellosta S, Nathan BP, Orth M, Dong L-M, Mahley RW, Pitas RE (1995) Stable expression and secretion of apolipoproteins E3 and E4 in mouse neuroblastoma cells produce differential effects on neurite outgrowth J Cell Biol 270:27063-27071.

Blottner D, Bruggemann W, Unsicker K (1989) Ciliary neurotrophic factor supports target-deprived preganglionic sympathetic spinal cord neurons. Neurosci Lett 105:316-320.

Boyles JK, Zoellner CD, Anderson LJ, Kosik LM, Pitas RE, Weisgraber KH, Hui DY, Mahley RW, Gebicke-Haerter PJ, Ignatius MJ (1989) A role for apolipoprotein E, apolipoprotein A-1, and low density lipoprotein receptors in cholesterol transport during regeneration and remyelination of the rat sciatic nerve. J Clin Invest 83:1015-1031.

Cardin AD, Hirose N, Blankenship DT, Jackson RL, Harmony JA, Sparrow DA, Sparrow JT (1986) Binding of a high reactive heparin to human apolipoprotein E: identification of two heparin-binding domains. Biochem Biophys Res Commun 134:783-789.

Connolly ES, Winfree CJ, Stern DM, Solomon RA, Pinsky DJ (1996) Exacerbation of stroke outcome in apolipoprotein E null mice: role of abnormal lipid metabolism in the pathogenesis of tissue injury following focal cerebral ischemia. Stroke 27:174A.

Davis S, Aldrich TH, Valenzuela DM, Wong V, Furth ME, Squinto SP, Yancopoulos GD (1991) The receptor for ciliary neurotrophic factor. Science 253:59-63.

Davis S, Aldrich TH, Ip NY, Stahl N, Scherer S, Farruggella T, DiStephano PS, Curtis R, Panayotatos N, Gascan H, Chevalier S, Yancopoulos GD (1993) Released form of CNTF receptor $\alpha$ component as a soluble mediator of CNTF responses. Science 259:1736-1739.

DeChiara TM, Vejsada R, Poueymirou WT, Acheson A, Suri C, Conover JC, Friedman B, McClain J, Pan L, Stahl N, Ip N, Kato A, Yancopoulos GD (1995) Mice lacking the CNTF receptor, unlike mice lacking CNTF, exhibit profound motor neuron deficits at birth. Cell 83:313-322.

Ernsberger U, Sendtner M, Rohrer H (1989) Proliferation and differentiation of embryonic chick sympathetic neurons: effects of ciliary neurotrophic factor. Neuron 2:1275-1284.

Goslin K, Banker G (1991) Rat hippocampal neurons in low-density culture. In: Culturing nerve cells (Goslin K, Banker G, eds), pp 251278. Cambridge, MA: MIT.
Holtzman DM, Pitas RE, Kilbridge J, Nathan B, Mahley RW, Bu G, Schwartz AL (1995) Low density lipoprotein receptor-related protein mediates apolipoprotein E-dependent neurite outgrowth in a central nervous system-derived neuronal cell line. Proc Natl Acad Sci USA 92:9480-9484.

Huang DY, Weisgraber KH, Strittmatter WJ, Matthew WD (1995) Interaction of apolipoprotein $\mathrm{E}$ with laminin increases neuronal adhesion and alters neurite morphology. Exp Neurol 136:251-257.

Hughes SM, Lillien LE, Raff MC, Rohrer H, Sendtner M (1988) Ciliary neurotrophic factor induces type-2 astrocyte differentiation in culture. Nature 335:70-73.

Ignatius MJ, Shooter EM, Pitas RE, Mahley RW (1987) Lipoprotein uptake by neuronal growth cones in vitro. Science 236:959-962.

Ip NY, Yancopoulos GD (1992) Ciliary neurotrophic factor and its receptor complex. Prog Growth Factor Res 4:1-17.

Ip NY, Li Y, van de Stadt I, Panayotatos N, Alderson RF, Lindsay RM (1991) Ciliary neurotrophic factor enhances neuronal survival in embryonic rat hippocampal cultures. J Neurosci 11:3124-3134.

Ip NY, Nye SH, Boulton TG, Davis S, Taga T, Li Y, Birren SJ, Yasukawa K, Kishimoto T, Anderson DJ, Stahl N, Yancopoulos GD (1992) CNTF and LIF act on neuronal cells via shared signaling pathways that involve the IL-6 signal transducing receptor component gp130. Cell 69:1121-1132.

Ip NY, Wiegand SJ, Morse J, Rudge JS (1993) Injury-induced regulation of ciliary neurotrophic factor mRNA in the adult rat brain. Eur J Neurosci 5:25-33.

Kamiguchi H, Yoshida K, Sagoh M, Sasaki H, Inaba M, Wakamoto H, Otani M, Toya S (1995) Release of ciliary neurotrophic factor from cultured astrocytes and its modulation by cytokines. Neurochem Res 20:1187-1193.

Kumar MA, Davidson VL (1992) Methods to identify and avoid artifactual formation of interchain disulfide bonds when analyzing proteins by SDS-PAGE. Biotechniques 12:198-202.

Larkfors L, Lindsay RM, Alderson RF (1994) Ciliary neurotrophic factor enhances the survival of Purkinje cells in vitro. Eur J Neurosci 6:1015-1025.

Laskowitz DT, Sheng H, Bart R, Joyner KA, Roses AD, Warner DS (1997) Apolipoprotein E-deficient mice have increased susceptibility to focal ischemia. J Cereb Blood Flow Metab, in press.

Lillien LE, Sendtner M, Raff MC (1990) Extracellular matrix-associated molecules collaborate with ciliary neurotrophic factor to induce type-2 astrocyte development. J Cell Biol 111:635-644.

Magal E, Burnham P, Varon S (1991) Effects of ciliary neuronotrophic factor on rat spinal cord neurons in vitro: survival and expression of choline acetyltransferase and low-affinity nerve growth factor receptors. Brain Res Dev Brain Res 63:141-150.

Magal E, Louis J-C, Oudega M, Varon S (1993) CNTF promotes the survival of neonatal rat corticospinal neurons in vitro. Dev Neurosci 4:779-782.

Mahley RW (1988) Apolipoprotein E: cholesterol transport protein with expanding role in cell biology. Science 240:622-630.

Masu Y, Wolf E, Holtmann B, Sendtner M, Brem G, Thoenen H (1993) Disruption of the CNTF gene results in motor neuron degeneration. Nature 365:27-32.

McDonald NQ, Panayotatos N, Hendrickson WA (1995) Crystal structure of dimeric human ciliary neurotrophic factor determined by MAD phasing. EMBO J 14:2689-2699.

Mott HR, Campbell ID (1995) Four-helix bundle growth factors and their receptors: protein-protein interactions. Curr Opin Struct Biol 5:114-121.

Müller HW, Seifert W (1982) A neurotrophic factor (NTF) released from glial cultures supports survival and fiber outgrowth of cultured hippocampal neurons. J Neurosci 8:195-204.

Nathan BP, Bellosta S, Sanan DA, Weisgraber KH, Mahley RW, Pitas RE (1994) Differential effects of apolipoproteins E3 and E4 on neuronal growth in vitro. Science 264:850-852.

Pitas RE, Boyles JK, Lee SH, Hui D, Weisgraber KH (1987) Lipoproteins and their receptors in the central nervous system. Characterization of the lipoproteins in cerebrospinal fluid and identification of apolipoprotein B,E (LDL) receptors in the brain. J Biol Chem 262:14352-14360.

Poirier J, Hess M, May PC, Finch CE (1991) Astrocytic apolipoprotein E mRNA and GFAP mRNA in hippocampus after entorhinal cortex lesioning. Mol Brain Res 11:97-106. 
Rall Jr SC, Weisgraber KH, Mahley RW (1986) Isolation and characterization of apolipoprotein E. Methods Enzymol 128:273-287.

Rende M, Muir D, Ruoslahti E, Hagg T, Varon S, Manthorpe M (1992) Immunolocalization of ciliary neurotrophic factor in adult rat sciatic nerve. Glia 5:25-32.

Riddle DR, Lo DC, Katz LC (1995) NT-4-mediated rescue of lateral geniculate neurons from effects of monocular deprivation. Nature 378:189-191.

Saadat S, Sendtner M, Rohrer H (1989) Ciliary neurotrophic factor induces cholinergic differentiation of rat sympathetic neurons in culture. J Cell Biol 108:1807-1816.

Sahenk Z, Seharaseyon J, Mendell JR (1994) CNTF potentiates peripheral nerve regeneration. Brain Res 655:246-250.

Sendtner M, Kreutzberg GW, Thoenen H (1990) Ciliary neurotrophic factor prevents the degeneration of motor neurons after axotomy. Nature 345:440-441.

Sendtner M, Stöckli KA, Thoenen H (1992) Synthesis and localization of ciliary neurotrophic factor in the sciatic nerve of the adult rat after lesion and during regeneration. J Cell Biol 118:139-148.

Sendtner M, Gotz R, Holtmann B, Escary JL, Masu Y, Carroll P, Wolf E, Brem G, Brulet P, Thoenen H (1996) Cryptic physiological trophic support of motoneurons by LIF revealed by double gene targeting of CNTF and LIF. Curr Biol 6:686-694.

Skaper SD, Varon S (1986) Age-dependent control of dorsal root ganglion neuron survival by macromolecular and low-molecular-weight trophic agents and substratum-bound laminins. Brain Res 389:39-46.

Skene JHP, Shooter EM (1983) Denervated sheath cells secrete a new protein after nerve injury. Proc Natl Acad Sci USA 80:4169-4173.

Slooter AJC, Tang M-X, van Duijn CM, Stern Y, Ott A, Bell K, Breteler MMB, Van Broeckhoven C, Tatemichi TK, Tycko B, Hofman A, Mayeux R (1997) Apolipoprotein E, $\epsilon 4$, and the risk of dementia with stroke. JAMA 277:818-821.

Sorbi S, Nacmias B, Piancentini S (1996) Apolipoprotein E genotypes and outcome after post-traumatic coma. Neurology 46:A307.

Stahl N, Yancopoulos GD (1994) The tripartite CNTF receptor complex: activation and signaling involves components shared with other cytokines. J Neurobiol 25:1454-1466.

Stahl N, Boulton TG, Farruggella T, Ip NY, Davis S, Witthuhn BA,
Quelle FW, Silvennoinen O, Barbieri G, Pellegrini S, Ihle JN, Yancopoulos GD (1994) Association and activation of Jak/Tyk kinases by CNTF-LIF-OSM-IL-6 $\beta$ receptor components. Science 263:92-95.

Stoll G, Mueller HW (1986) Macrophages in the peripheral nervous system and astroglia in the central nervous system of rat commonly express apolipoprotein E during development but differ in their response to injury. Neurosci Lett 72:233-238.

Stoll G, Mueller HW, Trapp BD, Griffin JW (1989) Oligodendrocytes but not astrocytes express apolipoprotein $\mathrm{E}$ after injury of rat optic nerve. Glia 2:170-176.

Strittmatter WJ, Roses AD (1995) Apolipoprotein E and Alzheimer's disease. Proc Natl Acad Sci USA 92:4725-4727.

Strittmatter WJ, Saunders AM, Schmechel DE, Pericak-Vance MA, Enghild J, Salvesen GS, Roses AD (1993a) Apolipoprotein E: highavidity binding to $\beta$-amyloid and increased frequency of type 4 allele in late-onset familial Alzheimer's disease. Proc Natl Acad Sci USA 90:1977-1981.

Strittmatter WJ, Weisgraber KH, Huang DY, Dong L-M, Salvesen GS, Pericak-Vance MA, Schmechel DE, Saunders AM, Goldgaber D, Roses AD (1993b) Binding of human apolipoprotein $E$ to synthetic $\beta$-amyloid peptide: isoform-specific effects and implications for lateonset Alzheimer disease. Proc Natl Acad Sci USA 90:8098-8102.

Unsicker K, Reichert-Preibsch H, Wewetzer K (1992) Stimulation of neuron survival by basic FGF and CNTF is a direct effect and not mediated by non-neuronal cells: evidence from single cell cultures. Brain Res Dev Brain Res 65:285-288.

Weisgraber KH (1994) Apolipoprotein E: structure and function relationships. Adv Protein Chem 45:249-307.

Weisgraber KH, Rall Jr SC, Mahley RW, Milne RW, Marcel YL, Sparrow JT (1986) Human apolipoprotein E. Determination of the heparin binding sites of apolipoprotein E3. J Biol Chem 261:2068-2076.

Wilson C, Wardell MR, Weisgraber KH, Mahley RW, Agard DA (1991) Three-dimensional structure of the LDL receptor-binding domain of human apolipoprotein E. Science 252:1817-1822.

Zannis VI, McPherson J, Goldberger G, Karathanasis SK, Breslow JL (1984) Synthesis, intracellular processing, and signal peptide of human apolipoprotein E. J Biol Chem 259:5495-5499. 